\title{
Exploration in to the Ergonomics of Sitting Posture of Lactating Mothers
}

\author{
Balagopal M Santhosh ${ }^{1}$, Malavika M D \\ Department of Mechanical Engineering ${ }^{1}$, \\ Department of Architecture ${ }^{2}$, \\ Govt.Rajiv Gandhi Institute of Technology \\ Kottayam, India
}

\begin{abstract}
The paper investigates the ergonomics of lactating mothers during feeding with different postures. The study was conducted to evaluate the lateral and anterior (longitudinal) changes in anthropometry, angles to be supported and sitting posture postpartum. As the study was to understand the visual perception, anthropometric models was used to find out the comfortable angles that varies in each subject, for assessment of dynamic balance while breast feeding. An online questionnaire survey was formulated considering the wider reach and easy accessibility to gather adequate data. The survey was conducted among the lactating mothers across Kerala. The responses of the online questionnaire were collected at various levels to properly find out the role of adequate support, on providing a comfortable and healthy breastfeeding experience for both mother and baby. Convergence of data was observed for the live case study using motion capture and the online survey and the optimum angle of recline and anthropometric positioning of the baby to the mother was determined.
\end{abstract}

Keywords-Anthropometry; Postpartum; breastfeeding; ergonomics; posture.

\section{INTRODUCTION}

Ergonomics is the study of the interrelationships between the machines and its human users. Ergonomics has various domains of which most crucial is anthropometry (anthropometry is the study of body measurement).Studies show that infant feeding decisions are influenced by a variety of factors individual to each woman and her family, the establishment and maintenance of breastfeeding is the primary objective of postnatal care. Despite of this fact, by 4 months breastfeeding has fallen to $28 \%$ of the total lactating mothers , despite evidence of long-term health benefits for both mother and baby (D Fraser et al.,2006). Many women consider breastfeeding to be an instinctive skill and may become disheartened in the early days, even if they have previous experience of breastfeeding. Optimal positioning and attachment of the baby at the breast are skills that are individual to each mother/baby. These are crucial to continued breastfeeding and the avoidance of postnatal problems. To achieve good attachment, the baby should be placed in close apposition to the mother, with its head and body in a straight line.

Backache is one of the most commonly reported, nontransient, postpartum problems. Lack of mobility in labour, poor positioning when bathing and feeding the baby and manoeuvering the baby in and out of cars, especially when carried in car seats, may all contribute to continuing backache. Ergonomically designed seating is important for long time seated lactating mothers to increase their productivity and also to reduce low back injuries due to use of poorly designed products in ergonomic aspects. In addition, ergonomically designed products increase the seating comfortability of the users. This paper discusses the importance of an ergonomic approach to the postures of a breastfeeding mother. It is now recognised that inadequate support, advice and treatment can impact quite considerably upon a woman's daily life, her relationships with family and friends and her parenting abilities. This paper provides an overview of the management of postnatal care and breastfeeding, and the anthropometric factors most likely to promote mothers health and well-being.

Today the scope of specified designs based on the anthropometry of lactating mothers lays in its ability to make their life comforting in sense of low physical pain and enhancing their experience of bringing a new-born into the world at its best.

\section{LITERATURE REVIEW}

\section{A. Postnatal care and management}

Postnatal care and management is the impetus of this paper as proper postpartum care and feeding posture affects the mother significantly. It was found through studies (D.Fraser et al.,2006) that despite of several isolated medical conditions such as nerve root pain (sciatica) that caused problems while breastfeeding and holding the baby, the most common was the back aches caused due to the improper posture while feeding. It was also found in a later research that shift in Body Centre of Mass (BCM) postpartum (Robert DC et al.,2019) can cause similar pain. Posture correction and better apposition of the baby was suggested in the above works.

\section{B. Design of an ergonomically efficient chair}

The paper [11] discussed the geometric parameters required in the design of an ergonomically efficient chair. This study charted out the basic design requirements of an ergonomically efficient chair from an anatomical and biological point of view. The force diagram shows (Fig.1) the forces applied in the body while seating. $\mathrm{X}, \mathrm{Y}$ and $\mathrm{Z}$ indicates the body forces and $\mathrm{A}, \mathrm{B}, \mathrm{C}$ and $\mathrm{D}$ indicates the reaction force from chair. 
The design requirements are as follows :

- $\quad$ Placement of the primary back support over the lower lumbar spine where most postural back symptoms are located (Fig. 2: X-Back support)

- $\quad$ The provision of a minimum angle of 105 degrees between the trunk and the thigh to help preserve the lumbar curve

- Provision of an open or recessive space for the posteriorly projecting sacrum and buttocks. This free space permits constant contact with tine primary lower lumbar back support.

- $\quad$ The upper limit of the convex primary lower lumbar back support in the short-backed "straight" chair should be well below the lower angles of tine scapulae. This permits unrestricted posterior placement of the shoulders for relaxing change of position in the chair.

- The shoulder support in high-backed chairs is secondary to the lumbar support, placed at a minimum angle of 105 degrees with the seat.

- Increase of angle of back of seat is pivoted on a point in line with the hip joint. This permits maintenance of contact with the primary lower lumbar support.

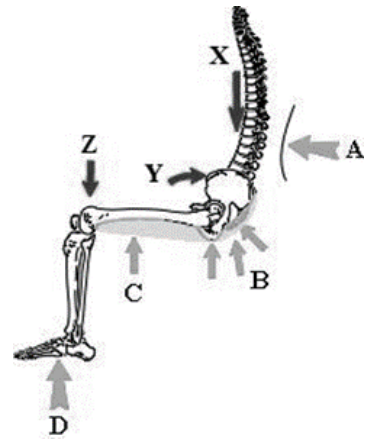

Fig 1. Force diagram

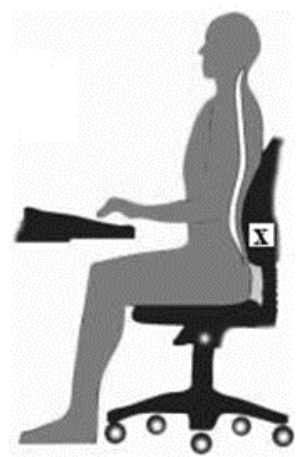

Fig 2. Lumbar support
Figures 1 \& 2 (source: study done by R.A.R.C. Gopura, K.G.A.H Amarasena,2008)

In the design of ergonomically efficient chair four basic parts of the chair are considered: Seat, back rest, hand rest and legs. The design includes 06 degree of freedoms (DOFs) for back rest (with back rest carrier), 10 DOFs for both hand rests (with hand rest carriers) and 03 DOFs for seat. All together the chair has 20 degrees of freedoms (with the mobility of the chair on the floor). The height, posture and inclination of the back rest, arm rest and seat, swivel range of seat and chair mobility can be adjusted according to the users' necessity from the above 20 DOFs.

The basic design requirements were tabulated in Table.1 (RARC Gopura et al.,2008)
Table 1 : Adjustable ranges of design considerations

\begin{tabular}{|l|l|}
\hline Design Specification & Adjustable range \\
\hline Arm rest height & $18.04 \mathrm{~cm}-26.93 \mathrm{~cm}$ \\
\hline Back rest height & $15.24 \mathrm{~cm}-25.4 \mathrm{~cm}$ \\
\hline Back rest angle & $100^{\circ}-120^{\circ}$ \\
\hline Seat height & $38 \mathrm{~cm}-56 \mathrm{~cm}$ \\
\hline
\end{tabular}

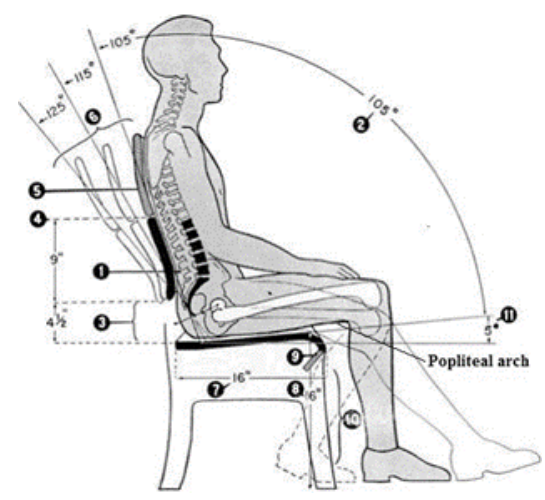

Fig 3. Design requirements

Figure:3 (source: study done by R.A.R.C. Gopura, K.G.A.H. Amarasena,2008)

\section{OBJECTIVES AND SCOPE OF STUDY}

The primary scope of this study was to understand the importance of ergonomics of lactating mothers. The study was also focused on how much it will differ from the design of an Ergonomically Efficient Chair for prolonged workers (RARC. Gopura et al.,2008). Owing to the subjective nature of the topic, the study was based on deciding the adjustable range of design specifications required for an ergonomically designed product that can assist in breast feeding

The objectives of the study are listed below :

- Anthropometry of lactating women in sitting position.

- Understanding the physical comfort of women during the feeding process under various aspects:

a: Time

b: Position

c: Dimensions

d: comfort

- $\quad$ Analyse when a comfortable posture can be attained and find the design specifications for the same.

\section{RESEARCH METHODOLOGY}

As the study was concentrated on ergonomics of lactating mothers, it needed a systematic and appropriate research methodology to draw down to a perfect and accurate conclusion. The study was performed in two parts. The first part being the compilation of required information from secondary sources to understand the role of ergonomics as tool in enhancing the efficiency of the user and second part being the research looking at certain cases wherein anthropometry as a tool has design specifications for comfortable feeding and caring for both mother and the baby. As the study was focused 
on the requirements and design specifications for an adjustable range of degree of freedom (DOF), the study was to involve preparing an online questionnaire. Number of degrees of freedoms to be provided was identified from this data. This was followed by data collection through live case study and changeover time was determined through a linear mixed model analysis. Collected responses was used to draw a conclusion through a quantitative approach.

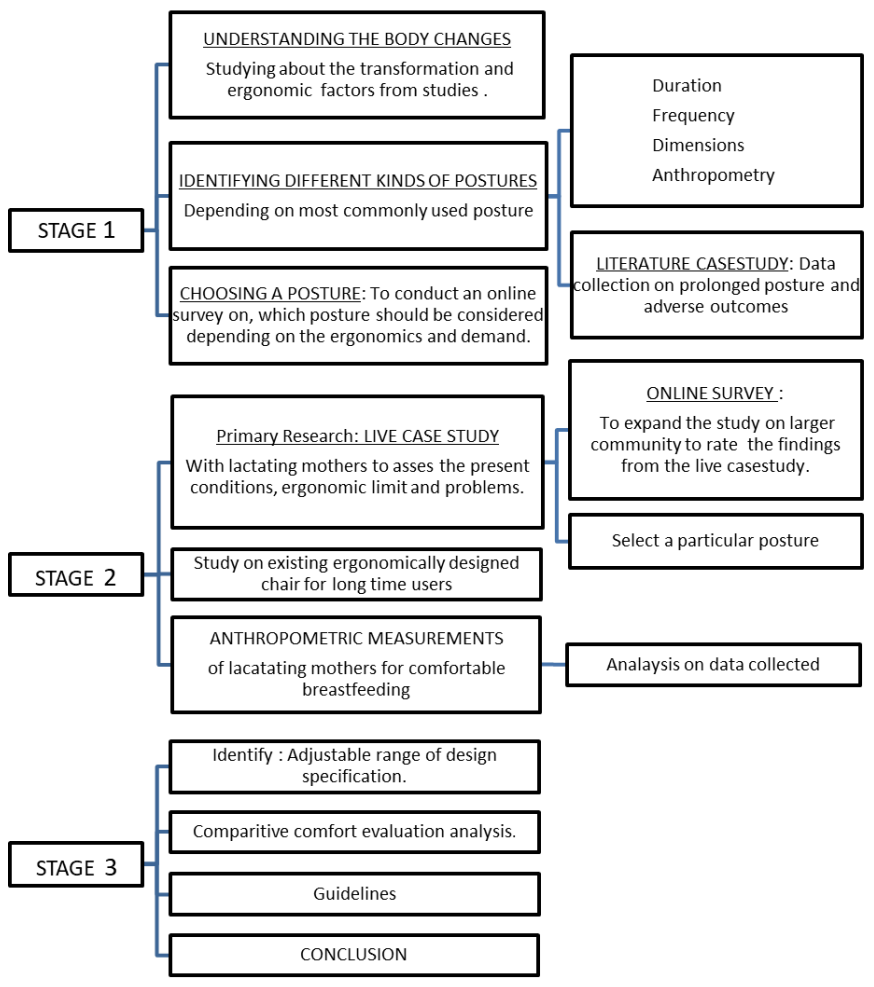

Fig 4. Research methodology

\section{A. Category selection}

Three major factors were considered while selecting the volunteers for the study, which were:

- They must come under 4 weeks -8 months postpartum, co-operating with the study.

- They must come under an age group between 18-40 years

- They must not have any neurological conditions that affect normal balance.

The above factors were used to select the volunteers for the live breast feeding study and the screening of online survey responses were also based on the above 3 factors.

\section{B. Questionnaire survey}

An online questionnaire survey was formulated considering the wider reach and easy accessibility to gather adequate data. The beginning of the questionnaire dealt with the personal information and breastfeeding experience. The respondents were asked to rate comfortable breastfeeding period such as initial days, 1 month, 4 months and 8 months postpartum after delivery with least or without any physical pain on a scale of 1 to 5,1 being the most painful and 5 being the most comfortable. The questionnaire continued, to choose a comfortable posture for breast feeding and about the parts of body which should be supported in order bear the weight of the baby for a long time as well as to remain relaxed and comfortable. Questions were asked about the requirements and needs of a lactating mother.

\section{B1. Online questionnaire software/tools used}

The online survey was carried out using the open access Google forms survey tool

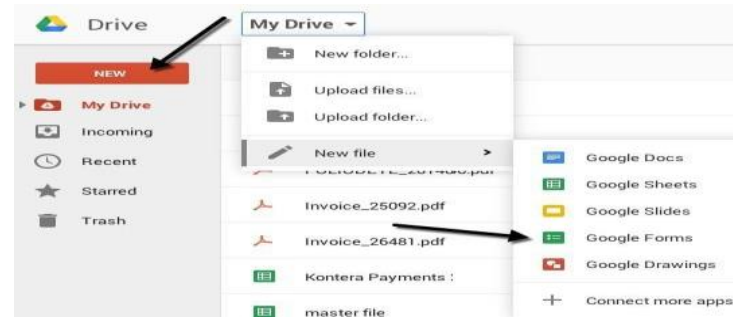

Fig 5. Google Forms

\section{Live Case study}

All participants selected for the case study were Indian citizens. The eligibility criteria were as follows:

- $\quad$ Normal-risk pregnancy

- $\quad$ No lower-extremity injury

- No neurological conditions that affect normal balance.

The study was conducted on subjects who were 0 to 8 months postpartum. Anthropometry was measured and then participants were made to do a static sitting trial and flexion movements throughout the period. For the study purpose, the time period was kept in the 15 - 30 min range.

From the video, Motion capture data was used in combination with the anthropometry to calculate the adjustment range required to acquire for ease of breastfeeding. Number of degrees of freedom (DOF) that should be provided was identified from this data. Changes over time were determined through a linear mixed model analysis.

As the centre of mass shifts there will be a change in the bend formed and angle for a comfortable sitting posture with the baby in the hands holding for long time. From the degree of freedoms identified, the study will contribute to the adjustable ranges of design specification for the same that can be adjusted according to the users' necessity. Design specification will be as follows:

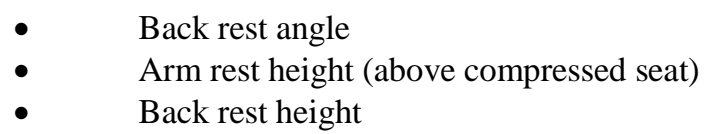




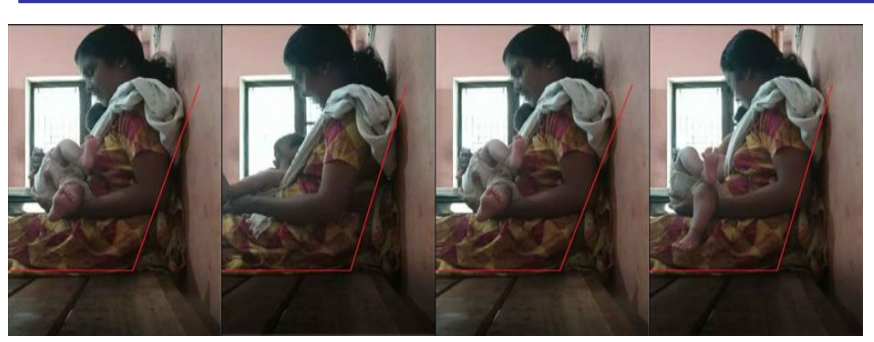

Fig 6. Live case study with motion capture

\section{DATA COMPILATION}

The data procured from the Online questionnaire and the live case study was compiled in graphical and tabular format for a systematic analysis of the projected factors affecting the ergonomic posture of a feeding mother

\section{A. Questionnaire / Online survey data}

The comfortable feeding conditions were plotted on a bar chart based on the responses with the scale of 1-5 rating for pain ( refer IV.B) and the percentage of relative responses in $\mathrm{x} \& \mathrm{y}$ axes respectively as shown in Fig.6

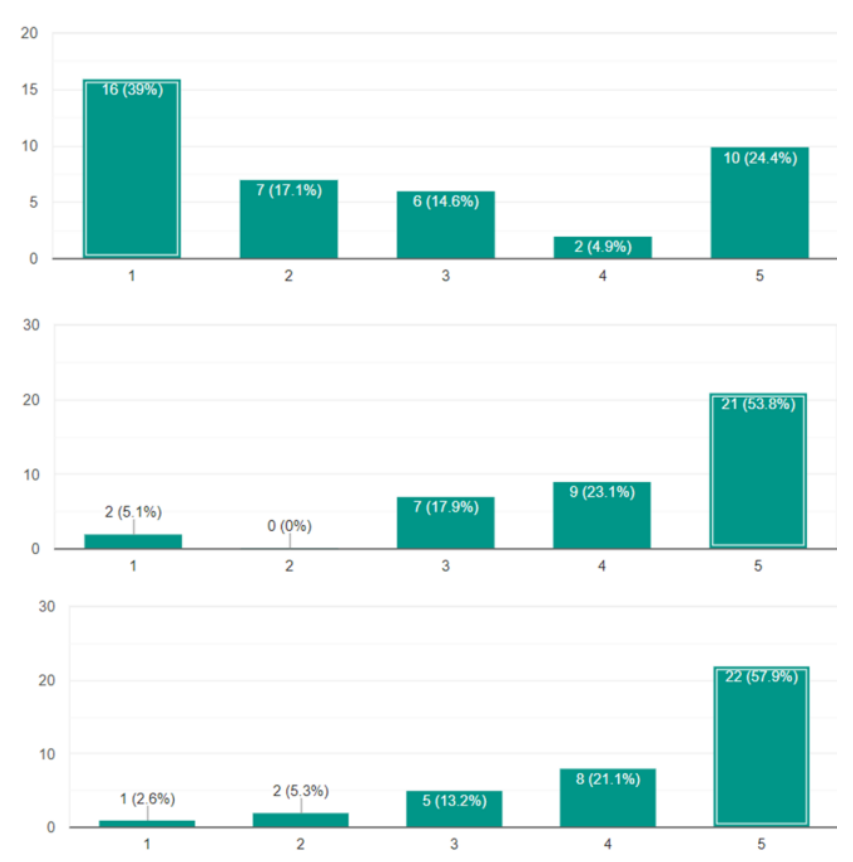

Fig 7. Comfort rating for $0,2,8$ months postpartum
The above chart shows the increase in the pain during the initial weeks as coming down to coming months. A significant increase in ratings could be observed which shows the shift to comfort by the end of 8 months at maximum.

The approximate time spent by a mother was plotted as a pie chart and is depicted in fig.7 and it is as follows

$<1$ hour: $46.3 \%$, 1-3 hours : $29.3 \%$ \& >3 hours : $24.4 \%$

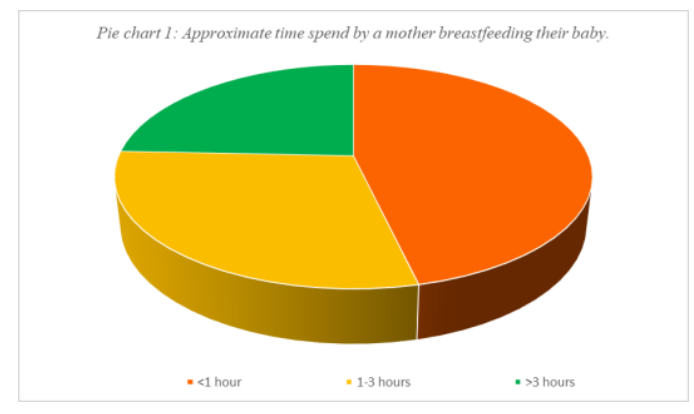

Fig 8. Approximate feeding time pie chart

The most preferred support responses were plotted as a pie chart depicted in Fig. 8 and it is as follows :

hands and back supported :73.20\%,, only hands supported: $19.50 \%$, only back supported: $6 \%$ \& none : $1.30 \%$

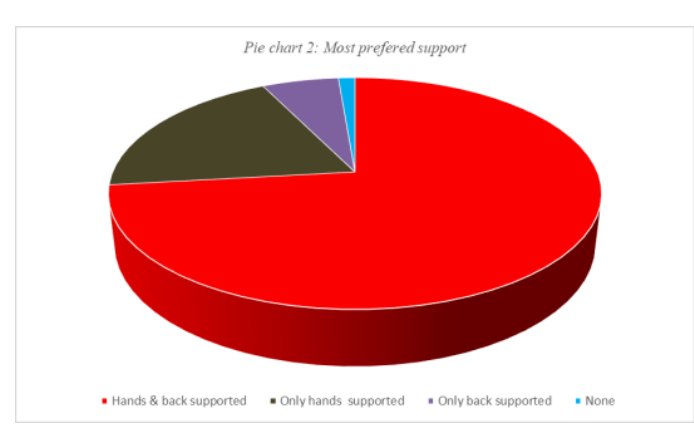

Fig 9. Most preferred support pie chart

The most comfortable feeding posture responses were plotted as a pie chart depicted in Fig. 9 and it is as follows :

sitting: $61 \%, 1-3$ hours : laying down:39\% \& none-: standing

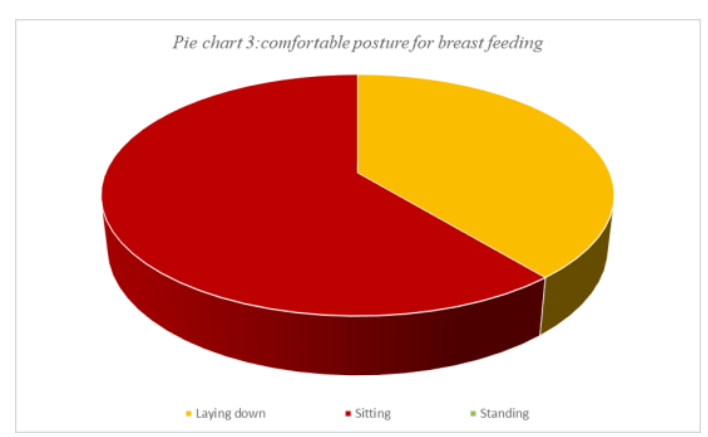

Fig 10. Most comfortable feeding posture pie chart 


\section{B. Live case study data}

1. Arm rest height

Comfortable arm rest heights were obtained from live case study provided by volunteers. The values thus obtain has been represented as table for easier analysis. The Table.2 shows the variation in the arm rest height as and when a mother breastfeed in sitting posture. In each individual a significant difference in height could be observed

\section{$2 . \quad$ Back rest angle}

Motion capture data was used in combination with the anthropometry to calculate the adjustment range of back rest angle required to acquire for ease of breastfeeding and was tabulated. Table. 3 shows the variation in back rest angle in each volunteer and the range of individual angular variation. Fig shows how an aligned and merged motion captured photo can be used to depict the range of variations

\section{$3 . \quad$ Back rest height}

Table.3 shows the variation in back rest height in each volunteer and the range of individual angular variation. Fig shows how an aligned and merged motion captured photo can be used to depict the range of variations

Table 2: Average arm rest height

\begin{tabular}{|l|l|l|l|l|l|l|l|l|l|l|}
\hline $\begin{array}{l}\text { Volunteer } \\
\text { no }\end{array}$ & 1 & 2 & 3 & 4 & 5 & 6 & 7 & 8 & 9 & 10 \\
\hline $\begin{array}{l}\text { Arm rest } \\
\text { height }(\mathrm{cm})\end{array}$ & 17 & 26 & 14 & 17 & 13 & 19 & 24 & 18 & 15 & 12 \\
\hline
\end{tabular}

Table 3: Back rest angle and height range

\begin{tabular}{|l|l|l|l|l|}
\hline $\begin{array}{l}\text { Volu } \\
\text { nteer } \\
\text { No }\end{array}$ & $\begin{array}{l}\text { Min back } \\
\text { rest angle }\end{array}$ & $\begin{array}{l}\text { Max } \\
\text { back } \\
\text { rest } \\
\text { angle }\end{array}$ & $\begin{array}{l}\text { Min } \\
\text { back } \\
\text { rest } \\
\text { height } \\
\text { (cm) }\end{array}$ & $\begin{array}{l}\text { Max } \\
\text { back } \\
\text { rest } \\
\text { height } \\
\text { (cm) }\end{array}$ \\
\hline 1 & $114^{\circ}$ & $120^{\circ}$ & 30 & 35 \\
\hline 2 & $100^{\circ}$ & $107^{\circ}$ & 27 & 30 \\
\hline 3 & $99^{\circ}$ & $106^{\circ}$ & 38 & 42 \\
\hline 4 & $106^{\circ}$ & $114^{\circ}$ & 34 & 38 \\
\hline 5 & $100^{\circ}$ & $118^{\circ}$ & 35 & 39 \\
\hline 6 & $104^{\circ}$ & $113^{\circ}$ & 35 & 40 \\
\hline 7 & $103^{\circ}$ & $109^{\circ}$ & 26 & 32 \\
\hline 8 & $113^{\circ}$ & $118^{\circ}$ & 29 & 34 \\
\hline 9 & $101^{\circ}$ & $117^{\circ}$ & 24 & 32 \\
\hline 10 & $104^{\circ}$ & $115^{\circ}$ & 34 & 40 \\
\hline
\end{tabular}

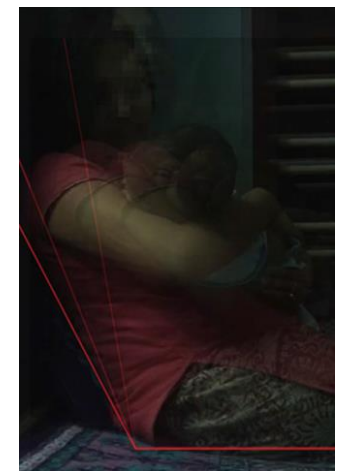

Fig 11. Volunteer 5: back rest angle, aligned and merged

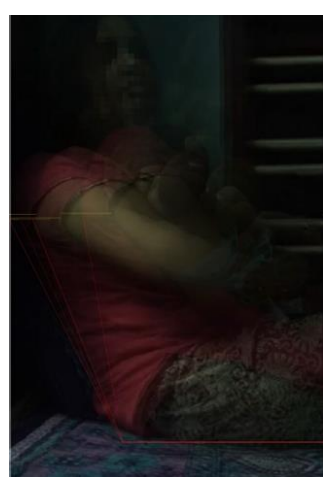

Fig 12. volunteer 5: back rest height, aligned and merged

\section{RESULTS AND CONCLUSIONS}

\section{A. Results}

- It was observed from Table.2 that the adjustable range of average arm rest height varies from $11 \mathrm{~cm}-26 \mathrm{~cm}$.

- The adjustable range of average back rest angle and back rest height is between $99^{\circ}-120^{\circ}$ and $20 \mathrm{~cm}$ respectively as obtained from Table. 3 .

Increased postpartum breast mass and/or persistent joint laxity may be the cause of curvature change in the lumbar spine postpartum. Thus, poor positioning when feeding the baby, which contribute to continuing backache can be reduced or avoided. Fig.12 shows the variation in the back rest angle while a mother breastfeeds in sitting posture with respect to time.

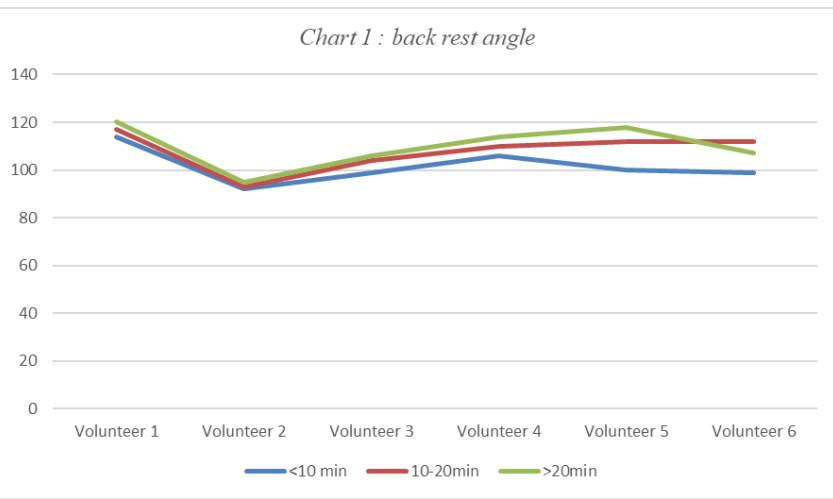

Fig 13. Back rest angle variation

In each individual a significant difference in angle could be observed. As the weight is being carried in their respective hands, a comfortable back rest angle is attained naturally in order to support the load.

- A significant increase in the range of arm rest height was observed from the live case study provided by respondents.. Hence it was concluded that the adjustable range of arm rest height is between $11 \mathrm{~cm}$ to $26 \mathrm{~cm}$ when compared to the $18 \mathrm{~cm}$ $-27 \mathrm{~cm}$ range of design specifications provided for an ergonomically designed chair for normal long term workers.

- The results obtained from the study with volunteers was found to converge with the results from the normal study with slight quantifiable variations by 99 degree to 120 degree.

- Using Motion capture data, in a combination with the anthropometry to calculate the design specification required for comfortable back rest height required for the ease of breastfeeding lies in between the range of $24 \mathrm{~cm}$ to $42 \mathrm{~cm}$ when compared to the $15 \mathrm{~cm}-25 \mathrm{~cm}$ range of design specifications provided for an ergonomically designed chair for normal long term workers.

\section{B. Conclusions}

By analyzing the responses collected through online questionnaire surveys using statistical methods and pictorial representations along with the data collected from live case study, the exploration into ergonomics of sitting position of a 
lactating mother, brought down certain serious conclusions as follows:

- Results of all the two analyses performed, clearly revealed the significant role of adequate support while breastfeeding in a prolonged siting posture by highlighting the increase in need for an ergonomically designed product for lactating mothers.

- Using Motion capture data, in a combination with the anthropometry on the responses pointed out the positive relationship between the rate of change in the back rest angle with respect time spend by the volunteers, which is due to the load (weight of the baby) that acts directly downwards at the lumber support part of the body. Thus by observing the above keys results we could conclude this study by restating the following:

1. Ergonomically designed products does have a major role in enhancing as well as providing comfort and support in the daily life of lactating mother.

2. Application of these design specifications in anthropometry creates new scope for ergonomics and also for wellbeing of lactating mothers in future.

- Future scope: The data collected using online questionnaire survey as well as from live study could be used in future detailed study on the area which have been omitted due to limited time span. The ergonomic parameters obtained from this study can be used to design a mechanism that can aid in breast feeding and thereby reducing backpain while feeding.

\section{ACKNOWLEDGMENTS}

The authors thank their guides Prof.Antony Jacob and Ar.Anrup K Nair for imparting technical prowess and wholehearted guidance for this research. The authors also thank Dr.Shobha Venkat for her guidance and suggestions that helped in the fruition of this research.

\section{REFERENCES}

[1] Diane M. Fraser, Lindsay, "Postnatal management and breastfeeding", Obstetrics, Gynaecology and Reproductive Medicine, Vol 16, Issue 2, pp 65-71,April 2006

[2] Thompson, J.F., Roberts, C.L., Ellwood, D.A ,"Prevalence and persistence of health problems after childbirth: associations with parity and method of birth", Birth, Vol 29, pp 83-94, 2002.

[3] Glazener CM, Abdalla M ,Stroud P ,Naji S ,Templeton A, Russell IT, "Postnatal maternal morbidity: extent, causes, prevention and treatment.” Br J Obstet Gynaecol. Vol 102, pp 282-287, 1995.

[4] Catena, Robert \& Campbell, Nigel \& Connor Wolcott, W \& A Rothwell, Sarah. (2019). Anthropometry, standing posture, and body center of mass changes up to 28 weeks postpartum in Caucasians in the United States. Gait \& Posture. 70 10.1016/j.gaitpost.2019.03.009.

[5] Pai YC, Patton J , Centre of mass velocity-position predictions for balance control, Journal of Biomechanics 1997Apr;30(4):347-354

[6] Mullaney L, O'Higgins AC, Cawley S, Kennedy R, McCartney D, Turner MJ. Breast-feeding and postpartum maternal weight trajectories. Public Health Nutr 2016 Jun; 19(8): 1397-1404

[7] Ignatius et al. 1993. Journal of Human Ergology, 22:83-93.

[8] Keegan J. J. Alterations of the Lumbar Curve Related to Posture and Seating. Journal of Bone and Joint Surgery, 35:589-603.

[9] Wilke et al. 1999. Spine 24:755-62.

[10] Cho GJ, Yoon HJ, Kim EJ, Oh MJ, Seo HS, Kim HJ. Postpartum changes in body composition. Obesity (Silver Spring) 2011 Dec; 19(12): 2425-2428

[11] Gopura, Ruwan \& G. A. H. Amarasena, K. (2008). Design of an Ergonomically Efficient Chair. 